\title{
Adsorption Application for Removal of Hazardous Chloroform from Aqueous Solution by Nanocomposites Rectorite/Chitosan Adsorbent
}

\author{
Shiqian Li, Peijiang Zhou*, Ling Ding \\ College of Resource \& Environmental Science, Hubei Biomass-Resource Chemistry and Environmental \\ Biotechnology Key Laboratory, Wuhan University, Wuhan, China \\ Email: zhoupj@whu.edu.cn
}

Received March 2, 2011; revised April 11, 2011; accepted May 21, 2011

\begin{abstract}
A novel nanocomposite bioadsorbent rectorite/chitosan was prepared by controlling different mass ratios of chitosan to rectorite using the water phase intercalation technique. The structure of the bioadsorbent was characterized by Fourier transform infrared (FT-IR) spectroscopy, X-ray diffraction (XRD) and scanning electron microscopy (SEM), Transmission electron microscopy (TEM), respectively. The results showed that the chitosan had been inserted into the rectorite layer successfully. The adsorption properties of the nanocomposite adsorbent toward $\mathrm{CHCl}_{3}$ from aqueous solution were investigated. Adsorption results showed that both nanocomposite adsorbents with weight ratio of rectorite to chitosan of 3:1 and 5:1 exhibited higher adsorption capacities.
\end{abstract}

Keywords: Nanocomposite Bioadsorbent; $\mathrm{CHCl}_{3}$ from Aqueous Solution; Adsorption.

\section{Introduction}

Chloroform (trichloromethane, $\mathrm{CHCl}_{3}$ ) has been observed in the environment over many years; in air [1], water [2] and soil pores [3]. It is also presented in treated potable water [4-6], indeed misinterpretation of the significance of this chloroform content led one government health authority to stop treating drinking water with disastrous consequences [7]. The sources of most of the environmental flux are poorly characterized and the purpose of this work is to draw together the current state of knowledge. In the course of this, the effects of the chloroform flux induced by human activity should be placed into the context of the overall ecotoxicological and human health effects arising from the total flux. Significant use has been made of the comprehensive prior assessments of Zok et al. [2] and an expanded version of this paper, containing details of all the determinations used, has been reported by Euro Chlor [8].

Owing to the adverse effects, a number of techniques such as biodegradable [9], photocatalytic oxidation [10], reverse osmosis, Wet Air Oxidation, and electro-deposition have been used to remove the toxic chloroform from aquatic environment [11]. However, these methods are not widely used due to their high cost and low feasibility for small-scale industries [12]. In contrast, the adsorption technique is one of the preferred methods for removal of chloroform because of its efficiency and low cost. Therefore, searching for efficient and affordable adsorption materials to purify the wastewater containing chloroform is of great significance [13].

Chitosan is a high molecular weight polysaccharide composed mainly of $\beta$-(1,4)-linked 2-deoxy-2-aminodglucopyranose units and partially of $\beta$-(1,4)-linked 2 -deoxy-2-acetamido-d-glucopyranose. It has the properties of biocompatibility, biodegradability and avirulence, etc. So chitosan has been used in many areas [14-16]. For example, due to its properties of high mechanical strength, hydrophilic character, good adhesion and non-toxicity, chitosan is usually applied as food additive, supporting material for chromatography and adsorbent polymer for chloroform removal [17-20], the cationic biopolymer chitosan can be intercalated in $\mathrm{Ca}^{2+}$-rectorite through cationic exchange and hydrogen bonding processes, the resulting nanocomposites showing interesting structural and functional properties. Polymer/clay nanocomposites are of great interest because they combine the structure of physical and chemical properties of both 
inorganic and organic materials. Compared to the pure polymers, these nanocomposites demonstrate excellent properties such as improved storage modulus [21], decreased thermal expansion coefficients [22], reduced gas permeability [23], and enhanced ionic conductivity [24].

Rectorite is a kind of layered silicate, the structure and characteristics are much similar to those of montmorillonite. It is referred as an interstratified clay mineral made of regular 1:1 stacking of dioctahedral mica-like layer (nonexpansible) and dioctahedral montmorillonite-like layer (expansible). The cations of $\mathrm{Na}^{+}, \mathrm{K}^{+}$and $\mathrm{Ca}^{2+}$ that contained lie in the interlayer region between $2: 1$ mica-like layers and 2:1 smectite-like layers, while the exchangeable hydrated cations reside in the latter. The REC structure can also cleave easily between smectite-like interlayers, forming monolithic REC layers of 2 $\mathrm{nm}$ thick. The interlayer cations can be exchanged easily by either organic or inorganic cations, and therefore rectorite has a property of water swelling similar to that of montmorillonite, which makes it possible to prepare chitosan/rectorite nanocomposites by solution-mixing processing technique. Therefore, in this study an attempt has been made to intercalate chitosan into the interlayers of the silicate, meanwhile, exhibiting this technique to develop new organic-inorganic hybrid materials provided with properties that are inherent to both types of components is also the purpose of the study [25].

In this study, a new clay/ploymer nanocomposite biosorbent were prepared by chitosan intercalation rectorite. Their structures were characterized by XRD, SEM and FT-IR techniques. It has been investigated that nanocomposite biosorbent have been used to remove $\mathrm{CHCl}_{3}$ from aqueous solution. rectorite/chitosan (REC/CS) nanocomposite biosorbent with the molar ratio of REC to CS of 3:1 showed good adsorption ability for $\mathrm{CHCl}_{3}$ from aqueous solution [26].

\section{Experimental}

\subsection{Materials}

Chitosan (CS) was obtained from Golden-shell Biochemical Co. Ltd., China (Zhejiang, China). Its degree of deacetylation and the apparent viscosity were determined as $92 \%$, and its average molecular weight was $2.1 \times 10^{5}$ (determined by GPC method) [27]. Rectorite (REC) refined from the clay minerals was provided by Hubei Mingliu Inc. Co. (Wuhan, China). All of the used chemical reagents in experiment were analytical grade, and solutions were prepared with ultrapure water. The stock solutions of $\mathrm{CHCl}_{3}(1000 \mathrm{mg} / \mathrm{L})$ were prepared from analytical grade $\mathrm{CHCl}_{3}$ using ultrapure water and serially diluted to working solutions of varying initial concentrations for experimental purpose. $1 \mathrm{~mol} / \mathrm{l} \mathrm{NaOH}$ and $\mathrm{HCl}$ were used to adjust the $\mathrm{pH}$ of the solutions.

\subsection{Preparation of CS-REC Nanocomposites Biosorbent}

The $2 \%(\mathrm{w} / \mathrm{v})$ solutions were prepared by dissolving an exact amount of CS in $1 \%(\mathrm{v} / \mathrm{v})$ acetic acid and stirring for about $4 \mathrm{~h}$ [14]. The resulting solution was added slowly into the pretreated REC suspensions under stirring at $50^{\circ} \mathrm{C}$ to obtain nanocomposites with initial REC/CS molar ratios of $1: 1,2: 1,3: 1,4: 1,5: 1$, The resulting mixture was agitated for 1 day, and then precipitated with $1 \mathrm{~mol} / \mathrm{L} \mathrm{NaOH}$. The formed composites were washed with distilled water until the solution became neutral. Finally the nanocomposites sorbent were dried at $50^{\circ} \mathrm{C}$ and ground to powder [28].

\subsection{Nanocomposites Biosorbent Characterizations}

FTIR spectra of nanocomposites sorbent before and after adsorption of metal ions are recorded in the frequency range of $4000-400 \mathrm{~cm}^{-1}$ on a Bomen FTIR, MB-series using a Nicolet - 5700, Thermo-Nicolet Fourier transform infrared spectrophotometer.

The X-ray diffraction (XRD) analyses were performed using a diffractometer type D/max-rA (X-650, HITACHI, Japan) with $\mathrm{Cu}$ target and $\mathrm{Ka}$ radiation $(\lambda=0.154 \mathrm{~nm})$ at $40 \mathrm{kV}$ and $50 \mathrm{~mA}$. The scanning rate was $1 \% \mathrm{~min}$ and the scanning scope of $2 \theta$ was $0.7-10^{\circ}$ at room temperature.

The morphologies of the REC, nanocomposite sorbent $(\mathrm{REC} / \mathrm{CS}=3: 1)$ were examined using a Hitachi XA-650 scanning electron microscope (SEM; Hitachi, Osaka, Japan). Samples were cryo-fractured from liquid nitrogen, and for morphological studies films of samples were mounted on metal grids, using double-sided adhesive tape, and coated with gold under vacuum.

Ultrathin films for transmission electron microscopy (TEM) were prepared by cutting from the epoxy block with the embedded nanocomposite sheet at room temperature using an LKB-8800 ultratome. The TEM micrographs were taken using a transmittance electron microscope [JEM-2010 FEF (UHR), JEOL, Japan] at an accelerating voltage of $200 \mathrm{kV}$.

\subsection{Adsorption Experiments}

All batch adsorption experiments were performed on a model KYC-1102 C thermostat shaker (Ningbo, China) with a shaking speed of $100 \mathrm{rpm}$. Typically, a $50 \mathrm{~mL}$ solution of known $\mathrm{CHCl}_{3}$ concentration and $0.025 \mathrm{~g}$ of chitosan/rectorite nanocomposite bioadsorbent were 
added into $100 \mathrm{~mL}$ glass flasks and then shook under 25 $\pm 0.2^{\circ} \mathrm{C}$. At the completion of preset time intervals, the aqueous samples were taken and then filtered. Residual $\mathrm{CHCl}_{3}$ concentration in supernatant was analyzed at $\lambda_{\max }$ $=536.0 \mathrm{~nm}$ using photolab 6100VIS type spectrophotometer (WTW, Germany). The same procedure has been used to study the effect of initial concentration and $\mathrm{pH}$ was adjusted either with $1 \mathrm{M} \mathrm{NaOH}$ or $1 \mathrm{M} \mathrm{HCl}$ as required. The $\mathrm{pH}$ of the solution was measured using a $\mathrm{pH}$ meter (Wuxi, China, METTLER TOLEDO-320). Experimental values of $\mathrm{CHCl}_{3}$ uptake capacities were the results of triplicate experiments reported as means. The concentration retained in the adsorbent phase $\left(q_{t}, \mathrm{mg} \mathrm{g}^{-1}\right)$ was calculated by the following equation:

$$
Q_{\mathrm{t}}=\left(\frac{c_{o}-c_{t}}{m}\right) v
$$

where $C_{\mathrm{o}}$ and $C_{\mathrm{t}}$ denote the initial and equilibrium $\mathrm{CHCl}_{3}$ concentrations $(\mathrm{mg} / \mathrm{L})$, respectively. ' $v$ ' was the volume of the solution in liters and ' $m$ ' was the mass of the adsorbent used (g).

The removal of $\mathrm{CHCl}_{3}(\eta)$ was calculated using the following equation:

$$
\eta \%=\frac{\left(c_{o}-c_{t}\right)}{c_{o}} \times 100
$$

\section{Results and Discussions}

\subsection{Characterization of Adsorbent}

\subsubsection{Fourier transform infrared (FTIR) studies}

As shown in Figure 1, the FTIR spectra of Na-rectorite sample. The band of $3640 \mathrm{~cm}^{-1}$ corresponds to the frame work water stretching vibrations. At $1630-1640 \mathrm{~cm}^{-1}$, there are the bands of flexing vibrations of free water at the edge of clay and in clay holes. The strong band at $1020 \mathrm{~cm}^{-1}$ is attributed to Si-O stretching vibrations. Si-O-Al flexing vibration band occurs at about $486 \mathrm{~cm}^{-1}$. The band at about $3440 \mathrm{~cm}^{-1}$ is attributed to adsorbed water-flexing vibrations [25]. In the spectra of the nanocomposites, the $\mathrm{N}-\mathrm{H}$ bonded to $\mathrm{O}-\mathrm{H}$ vibration band at $3448 \mathrm{~cm}^{-1}$ in CS shifts towards lower frequency [29], wider and stronger peaks are observed in all the REC/CS nanocomposites. This fact indicates that $-\mathrm{NH}_{2}$ and $-\mathrm{OH}$ groups of $\mathrm{CS}$ formed hydrogen bonds with the $-\mathrm{OH}$ group in REC which coincided with the CS/MMT nanocomposites [30]. At $1420 \mathrm{~cm}^{-1}$ (-NH deformation vibration in $\left.-\mathrm{NH}_{2}\right), 1027 \mathrm{~cm}^{-1}(-\mathrm{CO}$ stretching vibration in $\left.-\mathrm{COCH}_{3}\right), 2877 \mathrm{~cm}^{-1}(\mathrm{C}-\mathrm{H}$ stretching vibration in $\mathrm{CS})$ the peaks at these wave numbers were intact, indicating that the functional groups were not disturbed during the intercalation process. The appearance of all these peaks demonstrates that nanocomposites REC/CS (3:1) had been successfully prepared.

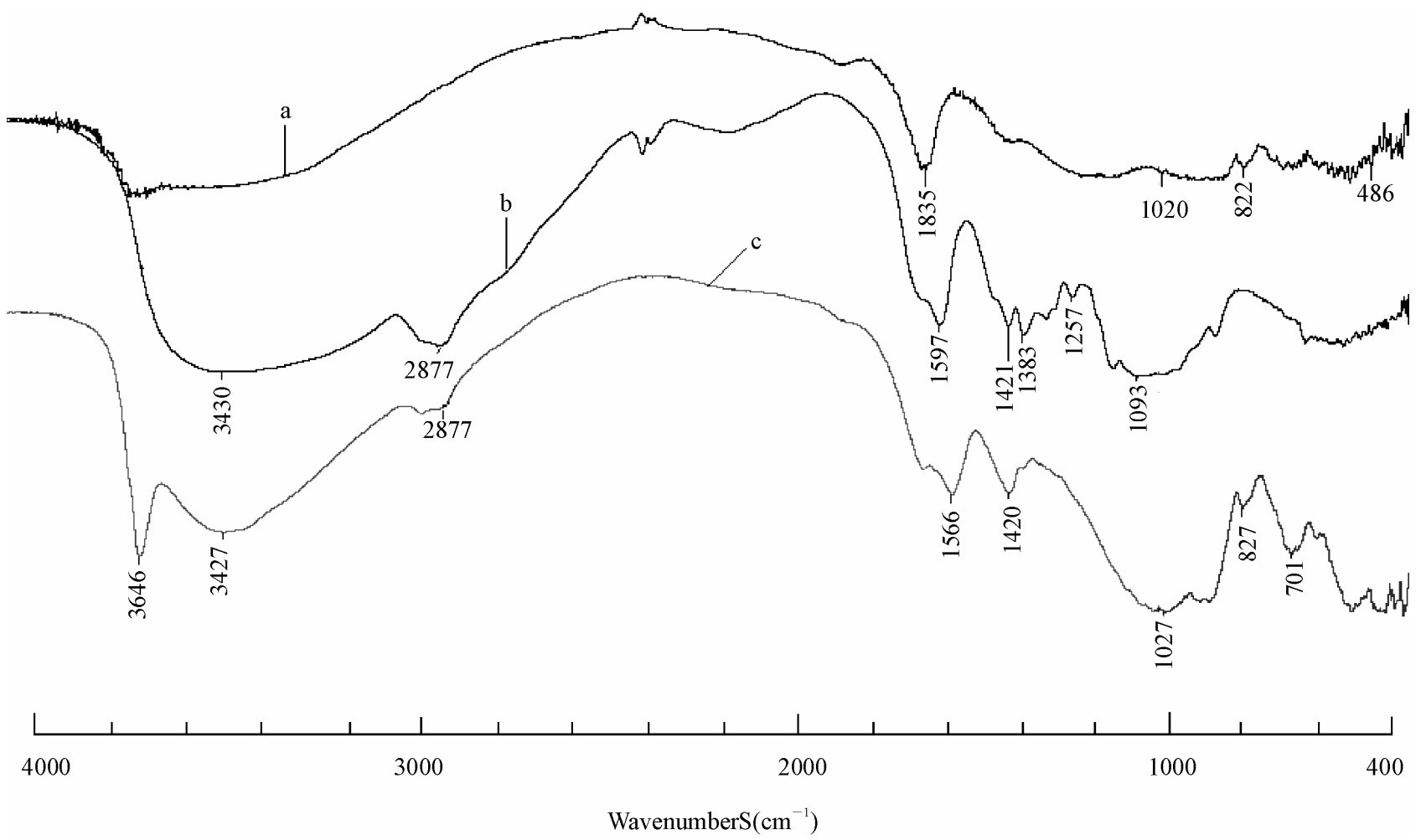

Figure 1. FT-IR spectra of raw rectorite (a); chitosan (b); 3:1 REC/CS (c). 


\subsubsection{X-Ray Diffraction (XRD) Studies}

XRD patterns of unmodified REC and XRD pattern of nanocomposites with different REC/CS ratios of 5:1; $3: 1$ were collected from $0.7^{\circ}$ to $10^{\circ}(2 \theta)$ and are show in Figure 2(a)-(c). It can be observed that unmodified rectorite exhibits $2 \theta=3.59^{\circ}$ and the $\Delta d_{L}$ value (the interlayer distance) is $2.45 \mathrm{~nm}$, calculated by the Bragg's equation [31]. In comparison with REC, the diffraction peaks of the composites rectorite shifted to the small-angle after being intercalated by chitosan, the results indicated that after the chitosan intercalated into the gallery of REC, a new composite material formed. It also can be observed from the Figure 2 that the layer spacing of the composite materials REC and the content of the chitosan was not proportional, when the ratio of amount of chitosan and REC is 1:5, the layer spacing has little change compared to REC merely, but when the ratio is $1: 3$, the layer spacing achieves to the maximum value of $2.78 \mathrm{~nm}$. Then with the increase of amount of chitosan, the layer spacing is no longer increased, but even tends to decrease, the possible reason is when the content of chitosan is inadequate, the driving force is not enough to carry out the intercalation into the REC. On the contrary, if the content of the chitosan is too much, chitosan molecular structure would be twisted together and wrapped rectorites, resulting in a larger structure, making it difficult to enter the narrow layer of rectories, which make good effects can't be achieved. So, as the figure shown, when the ratio is $3: 1$, the effect is best [28].

\subsubsection{Electron microscope studies}

The SEM micrographs of REC, nanocomposite biosorbent (b) is shown in Figure 3. On the SEM of REC (Figure 3(a)), the surface is smooth, but appears porous. On the SEM of nanocomposite sorbent (REC/CS) (Figure 3(b)), the chitosan molecule was largely carried on

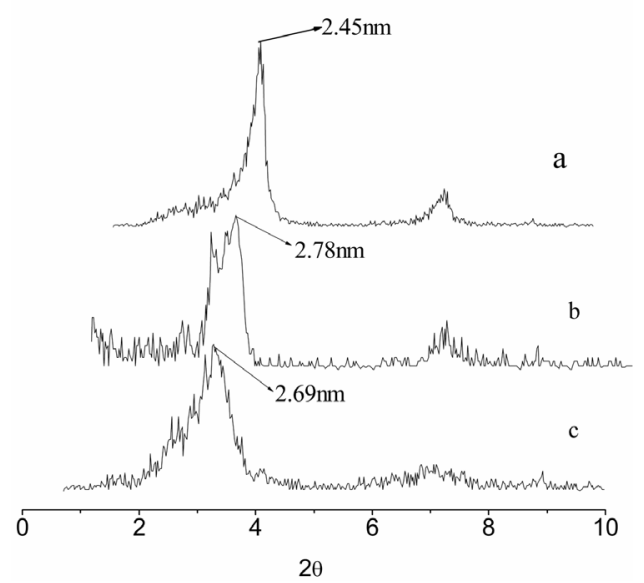

Figure. 2. XRD patterns of raw rectorites (a), 3:1REC/CS (b) and 5:1REC/CS (c).
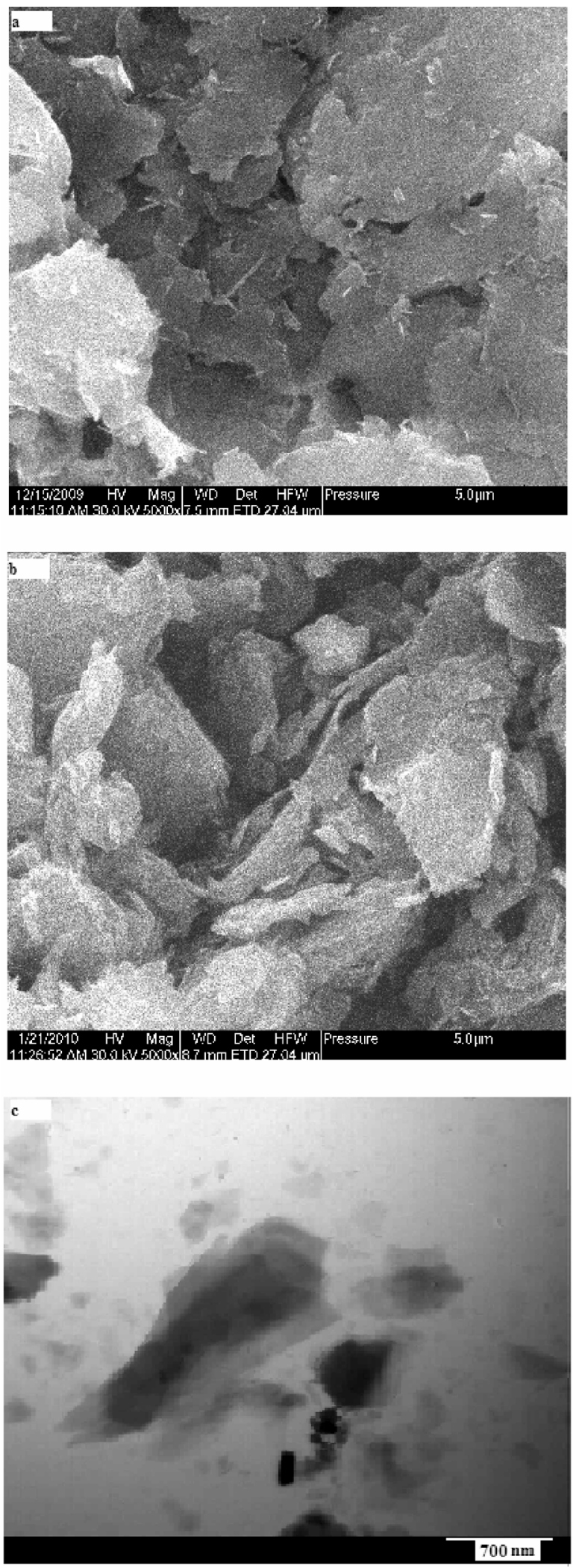

Figure 3. SEM images of REC (a) REC/CS; and (b) nanocomposite sorbent (REC/CS = 3:1) and (c) TEM images of nanocomposites sorbent (REC/CS = 3:1). 


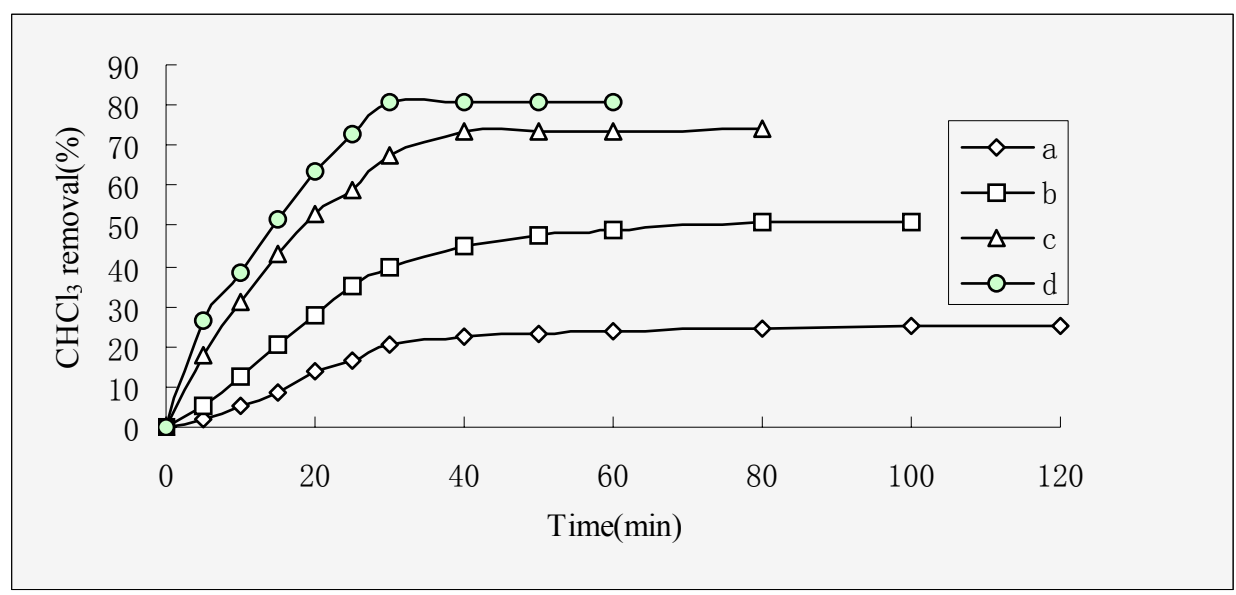

Figure. 4. Effect of different adsorbents on $\mathrm{CHCl}_{3}$ adsorption capacities, rectorites (a), chitosan (b), 5:1 REC/CS (c), 3:1 $\mathrm{REC} / \mathrm{CS}$ (d). Adsorption conditions: initial $\mathrm{CHCl}_{3}$ concentration $50 \mathrm{mg} / \mathrm{L}$; adsorbent dosage $0.5 \mathrm{~g} / \mathrm{L} ; \mathrm{pH} 6.8$; temperature $30 \pm$ $0.2^{\circ} \mathrm{C}$; stirring rate $120 \mathrm{rpm}$.

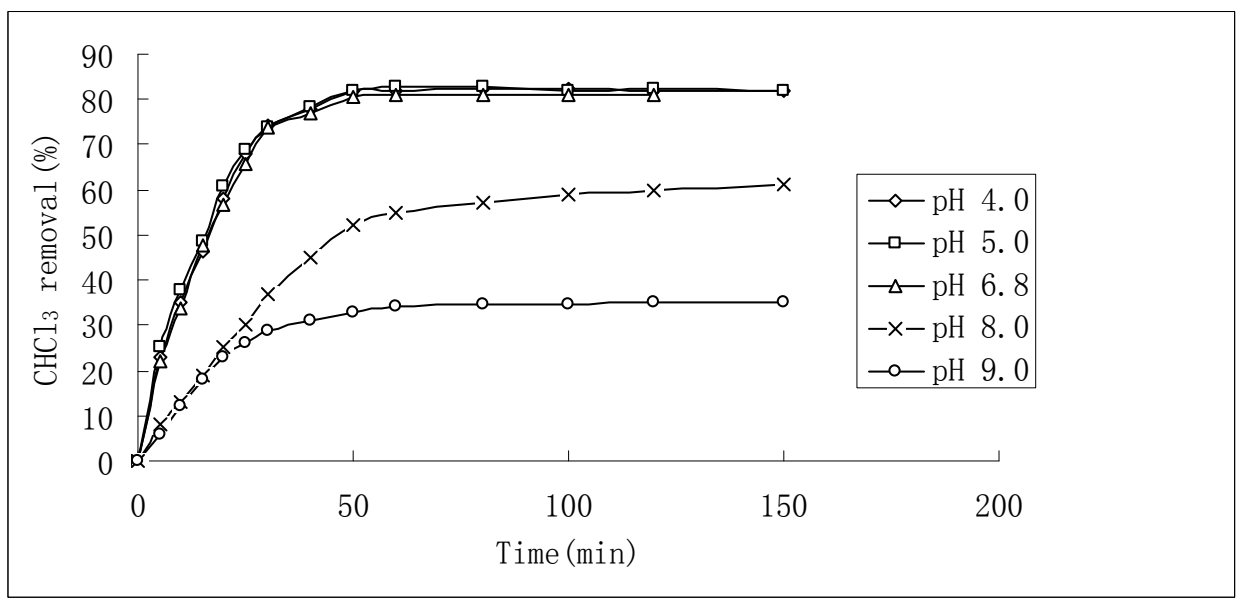

Figure 5. Effect of initial solution $\mathrm{pH}$ on $\mathrm{CHCl}_{3}$ adsorption by 3:1 REC/CS. Adsorption conditions: initial $\mathrm{CHCl}_{3}$ Concentration $50 \mathrm{mg} / \mathrm{L}$; adsorbent dosage $0.5 \mathrm{~g} / \mathrm{L}$; temperature $30 \pm 0.2^{\circ} \mathrm{C}$; stirring rate $120 \mathrm{rpm}$.

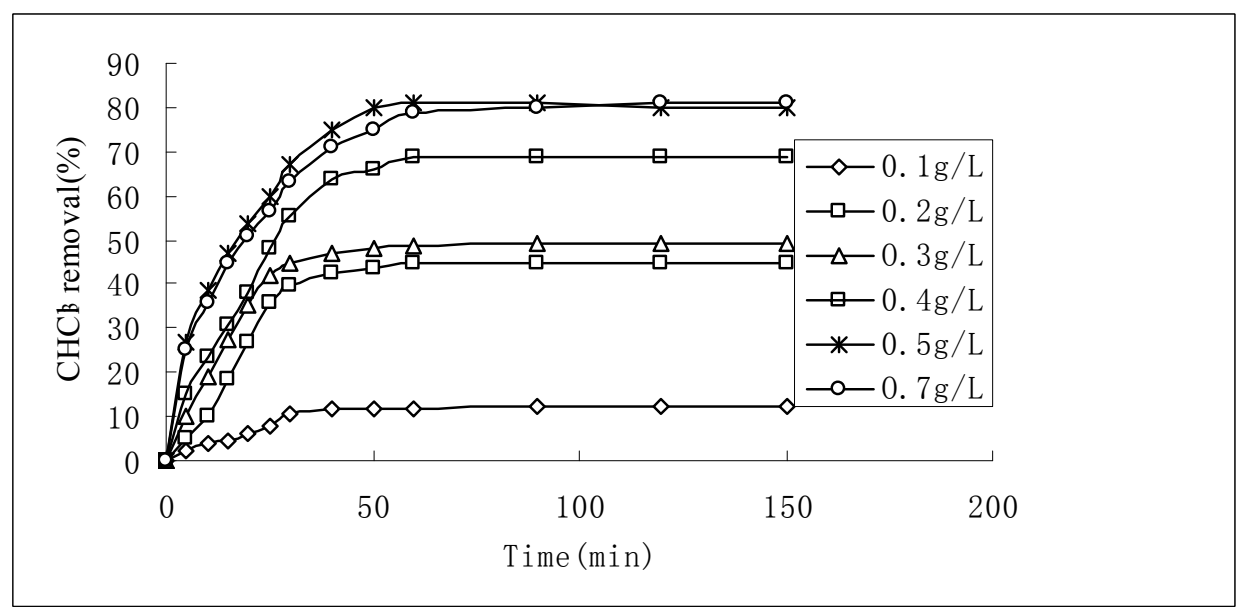

Figure 6. Effect of adsorption dosage on $\mathrm{CHCl}_{3}$ adsorption by 3:1 REC/CS. Adsorption conditions: initial $\mathrm{CHCl}_{3} \mathrm{Concentra}^{-}$ tion 50mg/L; $\mathrm{pH} 6.8$; temperature $30 \pm 0.2^{\circ} \mathrm{C}$; stirring rate $120 \mathrm{rpm}$. 
the surface of REC, therefore, the surface of the nanocomposite is microporous and have many active groups, But the other part was partly inserted into the REC layer spacing [31], getting through the interlayer hole of rectories, the fluffy surface of nano-composites making the surface area of nanocomposite increases, which increasing its adsorption capacity.

The TEM micrographs of nanocomposites were observed and are shown in (Figure 3(c)), it can be seen from the figure, rectories' structure appears flaky and have many gaps between layers, the chitosan macromolecules distributed in these gaps, observing from TEM, the composite particle appears a size with diameter of tens to hundreds nanometer, so it can be concluded that the composites was nanocomposite materials. Water solution intercalation method directly embed the polymer into the inorganic layer and remove the solution by using appropriate solvent to dissolve polymer and clay, then mixed and stirred to obtain nanocomposites. It also can be seen from TEM analysis, the prepared rectorite/chitosan composites was nanocomposite materials, the result was consistent with the water solution interaction technique [28].

\subsection{Adsorption Studies}

\subsubsection{Comparison of $\mathrm{CHCl}_{3}$ Adsorption with Different Adsorbent}

Figure 4 shows adsorption percent of $\mathrm{CHCl}_{3}$ as a function of contact time onto four different adsorbents, namely rectories (a), chitosan (b), REC:CS 5:1 (c), REC/CS 3:1 (d), respectively. The saturation adsorption capacities of $\mathrm{CHCl}_{3}$ onto the four adsorbents were measured as $25 \mathrm{mg} \mathrm{g}^{-1}, 51 \mathrm{mg} \mathrm{g}^{-1}, 73.6 \mathrm{mg} \mathrm{g}^{-1}$ and $81 \mathrm{mg} \mathrm{g}^{-1}$, respectively. The data indicated that the two REC/CS adsorbents showed higher adsorption capacities as compared with those of rectories and chitosan. On one hand, due to the intercalation of polymer chains usually increases the interlayer spacing relative to that of the pure REC [32], on the other hand, the introduction of chitosan, provided more available sites for $\mathrm{CHCl}_{3}$ adsorption due to a larger surface and smaller pore diameter compared with rectories [33]. The phenomenon has been proved by the result of XRD and SEM analysis.

At the same time, it took $100 \mathrm{~min}, 80 \mathrm{~min}, 40 \mathrm{~min}$ and $50 \mathrm{~min}$ to attain equilibrium for rectories, chitosan, REC/CS 3:1 and REC:CS 5:1, respectively. The $\mathrm{CHCl}_{3}$ removal increased dramatically and the adsorption equilibrium was achieved much faster with the introduction of chitosan. From the experimental data, it is observed that by introducing inorganic REC particles into the polymeric networks, the adsorption capacity seems to be affected significantly, especially in different time. This behavior is very clear. Nevertheless, one can conclude that this nanocomposite can be used in a wide short equilibration time.

\subsubsection{Effect of Initial pH Values on $\mathrm{CHCl}_{3}$ Adsorption Capacity}

Generally, the solution $\mathrm{pH}$ values are one of the important parameters controlling the adsorption of $\mathrm{CHCl}_{3}$ from aqueous solution onto solid polymeric adsorbent [34]. In order to investigated effect of initial solution $\mathrm{pH}$ values on $\mathrm{CHCl}_{3}$ removal, experiments were carried out using various $\mathrm{pH}$ levels in the range of $4.0-9.0$, as shown in Figure 5. It appears that the adsorption percent of $\mathrm{CHCl}_{3}$ onto $3: 1 \mathrm{REC} / \mathrm{CS}$ decreased from $81.8 \%$ to $22.0 \%$ after $60 \mathrm{~min}$ adsorption with increase in $\mathrm{pH}$ from 4.0 to 9.0 . This result indicated that the adsorption capacity decreased with the increase of initial solution $\mathrm{pH}$. The decrease of chloroform adsorption with increasing $\mathrm{pH}$ can be explained by the electrostatic interaction between the adsorbent surface and the $\mathrm{CHCl}_{3}$. Because chitosan has a positively charged surface below $\mathrm{pH} 6.5$ (point of zero potential). In acidic solution, hydrogen atoms $\left(\mathrm{H}^{+}\right)$in solution can protonate amine groups $\left(-\mathrm{NH}_{2}\right)$ of chitosan. As a result, the electrostatic interactions between $\mathrm{CHCl}_{3}$ and chitosan with positively charged surface increased in acidic solution [35].

\subsubsection{Effects of Adsorbent Dosage on $\mathrm{CHCl}_{3}$ Adsorption Capacity}

Adsorption dosage is another important parameter because it determines the capacity of an adsorbent for a given initial concentration of adsorbate. Effect of adsorbent dosage was studied on $\mathrm{CHCl}_{3}$ removal from aqueous solutions by varying the amount of $3: 1 \mathrm{REC} / \mathrm{CS}$ from $0.1 \mathrm{~g} \mathrm{~L}^{-1}$ to $0.7 \mathrm{~g} \mathrm{~L}^{-1}$ while keeping other parameters constant such as $50 \mathrm{mg} \mathrm{L}^{-1}$ initial $\mathrm{CHCl}_{3}$ concentration, initial solution $\mathrm{pH} 6.8$ and stirring rate $120 \mathrm{rpm}$. The $\mathrm{CHCl}_{3}$ removal increased from $12.1 \%$ to $81.2 \%$ with increasing adsorbent dosage from $0.1 \mathrm{~g} \mathrm{~L}^{-1}$ to $0.7 \mathrm{~g} \mathrm{~L}^{-1}$ (Figure 6). Initially, a rapid increase of adsorption with the increasing adsorbent dosage was attributed to availability of more adsorption sites [36]. However, further increase in adsorbent dosage to $0.7 \mathrm{~g} \mathrm{~L}^{-1}$ only leads to the adsorption percent increase by $0.2 \%$. At the same time, the amount adsorbed $\left(q_{e}\right)$ decreased from $60 \mathrm{mg} \mathrm{g}^{-1}$ to $57.6 \mathrm{mg} \mathrm{g}^{-1}$ when the adsorbent dosage increased from $0.1 \mathrm{~g} \mathrm{~L}^{-1}$ to $0.7 \mathrm{~g} \mathrm{~L}^{-1}$. The decrease of adsorption was due to the concentration gradient between adsorbent and adsorptive [37]. As a result, $0.5 \mathrm{~g} \mathrm{~L}^{-1}$ was the optimum adsorbent dosage for $\mathrm{CHCl}_{3}$ adsorption onto $3: 1 \mathrm{REC} / \mathrm{CS}$. This result was in agreement with the XRD analysis. 


\section{Conclusions}

A new nanocomposite adsorbent was prepared and characterized using the FTIR, XRD, SEM, TEM. The nanocomposite adsorbents for $\mathrm{CHCl}_{3}$ from aqueous solution were tested. The following conclusions can be made from this study:

1) The results confirm that when the ratio of the rectorite and chitosan is $3: 1$, the $\mathrm{pH}$ of the solution is 6.8 , the adsorption time is $40 \mathrm{~min}$, the dosage is $0.5 \mathrm{~g} / \mathrm{L}$ and the temperature is $30^{\circ} \mathrm{C}$, the adsorption capacity of $\mathrm{CHCl}_{3}$ onto nanocomposites were largest.

2) According to the comparison made with CS, REC adsorption efficiency on $\mathrm{CHCl}_{3}$, nanocomposite adsorbent on $\mathrm{CHCl}_{3}$ adsorption capacity significantly increased.

\section{Acknowledgements}

The authors thank for jointly supporting by the National Natural Science Foundation of China (20577036, 20777058, 20977070) and "863" Project of the Ministry of Science and Technology, PR China (2007AA06Z418).

\section{References}

[1] S. O_Doherty, P. G. Simmonds, D. M. Cunnold, H. J. Wang, G. A. Sturrock, P. J. Fraser, D. Ryall, R. G. Derwent, R. F. Weiss, P. Salameh, B. R. Miller and R. G. Prinn, "In situ Chloroform Measurements at Advanced Global Atmospheric Gases Experiment Atmospheric Research Stations from 1994 to 1998," Journal of Geophysics Research, Vol. 106, No. (D17), 2001, pp. 2042920444.

[2] S. Zok, J. -C. Boutonnet, C. de Rooij, V. Garny, A. Lecloux, R. Papp, R. S. Thompson, D. van Wijk, "EuroChlor Risk Assessment for the Marine Environment OSPARCOM Region: North Sea-Chloroform," Environment Monitor Assessment, Vol. 52, 1998, pp. 401-424. doi:10.1023/A:1006010515371

[3] E. G. Garrido-Ramírez, B. K. G. Theng and M. L. Mora, "Clays and Oxide Minerals as Catalysts and Nanocatalysts in Fenton-Like Reactions - A Review," Applied Clay Science, Vol. 47, No. 3-4, 2010, pp. 182-192. doi:10.1016/j.clay.2009.11.044

[4] J. Gibbons and S. Laha, "Water Purification Systems: A Comparative Analysis Based on the Occurrence of Disinfection by-Products," Environment Pollution, Vol. 106, No. 3, 1999, pp. 425-428. doi:10.1016/S0269-7491(99)00097-4

[5] S. K. Golfinopoulos, "The Occurrence of trihalomethanes in the Drinking Water in Greece," Chemosphere, Vol. 41, No. 11, 2000, pp. 1761-1767. doi:10.1016/S0045-6535(00)00062-X

[6] M. A. Stack, G. Fitzgerald, S. O Connell and J. K. James, "Measurement of Trihalomethanes in Potable and Recreational Waters Using Solid Phase Micro Extraction with Gas Chromatography-Mass Spectrometry," Chemosphere, Vol. 41, No. 11, 2000, pp. 1821-1826. doi:10.1016/S0045-6535(00)00047-3

[7] C. Anderson, "Cholera Epidemic Traced to Risk Miscalculation," Nature, Vol. 354, No. 6351, 1991, pp. 255-257. doi: $10.1038 / 354255 \mathrm{a} 0$

[8] European Chlorine, "Chloroform in the Environment: A Dossier,” Brussels, Belgium, May 2002.

[9] S. W. Zielhuis, J. F. W. Nijsen, L. Dorland, G. C. Krijger, A. D. vanhetSchip and W. E. Hennink, "Removal of Chloroform from Biodegradable Therapeutic Microspheres by Radiolysis," International Journal of Pharmaceutics, Vol. 315, No. 1-2, 2006, pp. 67-74. doi:10.1016/j.ijpharm.2006.02.010

[10] S. Yamazaki, A. Yoshida and H. Abe, "Photocatalytic Degradation of Chloroform in the Gas Phase on the Porous $\mathrm{TiO}_{2}$ Pellets: Effect of $\mathrm{Cl}$ Accumulated on the Catalyst Surface," Journal of Photochemistry and Photobiology A: Chemistry, Vol. 169, No. 1, 2005, pp. 191-196. doi:10.1016/j.jphotochem.2004.06.018

[11] A. Demirbas, "Heavy Metal Adsorption onto Agro-Based Waste Materials," Journal of Hazardous Materials, Vol. 157, No. 2-3, 2008, pp. 220-229. doi:10.1016/j.jhazmat.2008.01.024

[12] J. Acharya, J. N. Sahu, B. K. Sahoo, C. R. Mohanty and B. C. Meikap, "Removal of Chromium(VI) from Wastewater by Activated Carbon Developed from Tamarind Wood Activated with Zinc Chloride," Chemistry Engineer Journal, Vol. 150, No. 1, 2009, pp. 25-39. doi:10.1016/j.cej.2008.11.035

[13] L. A. Jonas and W. J. Svirbely, "The Kinetics of Adsorption of Carbon Tetrachloride and Chloroform from Air Mixtures by Activated Carbon," Journal of Catalysis, Vol. 24, No. 3, 1972, pp. 446-459. doi:10.1016/0021-9517(72)90128-5

[14] M. Darder, M. Colilla and E. Ruiz-Hitzky, "Biopolymer-Clay Nanocomposites Based on Chitosan Intercalated in Montmorillonite," Chemistry of Materials, Vol. 15, No. 20, 2003, pp. 3774-3780. doi:10.1021/cm0343047

[15] D. Karadag, S. Tok, E. Akgul, M. Turan, M. Ozturk and A. Demir, "Ammonium Removal from Sanitary Landfill Leachate Using Natural Gordes Clinoptilolite," Journal of Hazardous Materials, Vol. 153, No. 3, 2008, pp. 60-66. doi:10.1016/j.jhazmat.2007.08.019

[16] L. Peng, Siddaramaiah, H. K. Nam, et al., "Novel PAAm/Laponite Clay Nanocomposite Hydrogels with Improved Cationic Dye Adsorption Behavior," Composites: Part B, Vol. 39, No. 5, 2008, pp. 756-763. doi:10.1016/j.compositesb.2007.11.003

[17] J. W. Park, M. O. Park and K. K. Park, "Mechanism of Metal Ion Binding to Chitosan in Solution Cooperative and Intramolecular Chelations," Bulletin of Korean Chemical Society, Vol. 5, No. 3, 1984, pp. 108-112.

[18] A. H. Chen, C. Y. Yang, C. Y. Chen and C. W. Chen, "The Chemically Crosslinked Metal-Complexed Chitosans for Comparative Adsorptions of $\mathrm{Cu}(\mathrm{II}), \mathrm{Zn}(\mathrm{II}), \mathrm{Ni}(\mathrm{II})$ and $\mathrm{Pb}(\mathrm{II})$ Ions in Aqueous Medium," Journal of Hazardous Materials, Vol. 163, No. 2-3, 2009, pp. 1068- 
1075. doi:10.1016/j.jhazmat.2008.07.073

[19] E. Guibal, C. Milot, O. Eterradossi, C. Gauffier and A. Domard, "Study of Molybdate Ion Sorption on Chitosan Gel Beads by Different Spectrometric Analyses," International Journal of Biology Macromology, Vol. 24, No. 1, 1999, pp. 49-59. doi:10.1016/S0141-8130(98)00067-1

[20] S. Hasan, T. K. Ghosh, D. S. Viswanath and V. M. Boddu, "Dispersion of Chitosan on Perlite for Enhancement of Copper(Ii) Adsorption Capacity," Journal of Hazardous Materials, Vol. 152, No. 2, 2008, pp. 826837. doi:10.1016/j.jhazmat.2007.07.078

[21] K. J. Yao, M. Song, D. J. Hourston and D. Z. Luo, "Polymer/Layered Clay Nanocomposites: 2 Polyurethane Nanocomposites," Polymer, Vol. 43, No. 3, 2002, pp. 1017-1020. doi:10.1016/S0032-3861(01)00650-4

[22] L. A. Utracki, "Compressibility and Thermal Expansion Coefficients of Nanocomposites with Amorphous and Crystalline Polymer Matrix," European Polymer Journal, Vol. 45, No. 7, 2009, pp. 1891-1903. doi:10.1016/j.eurpolymj.2009.04.009

[23] A. Usuki, A. Tukigase and M. Kato, "Preparation and Properties of EPDM-Clay Hybrids," Polymer, Vol. 43, 2002, pp. 2185-2189. doi:10.1016/S0032-3861(02)00013-7

[24] J. H. Wu and M. M. Lerner, "Structural Thermal and Electrical Characterization of Layered Nanocomposites Derived from Na-Montmorillonite and Polyethers," Chemistry Materials, Vol. 5, No. 6, 1993, pp. 835-838. doi:10.1021/cm00030a019

[25] X. Y. Wang, Y. M. Du, J. W. Luo, B. F. Lin and J. F. Kennedy, "Chitosan/Organic Rectorite Nanocomposite Films: Structure, Characteristic and Drug Delivery Behaviour," Carbohydrate Polymer, Vol. 69, No. 1, 2007, pp. 41-49. doi:10.1016/j.carbpol.2006.08.025

[26] H. Kasgoz and A. Durmus, "Dye Removal by a Novel Hydrogel-Clay Nanocomposite with Enhanced Swelling Properties," Polymers for Advanced Technologies, Vol. 19, No. 7, 2008, pp. 838-845. doi:10.1002/pat.1045

[27] C. Q. Qin, Y. M. Du and L. Xiao, "Effect of Hydrogen Peroxide Treatment on the Molecular Weight and Structure of Chitosan," Polymer Degradation and Stability, Vol. 76, No. 2, 2002, pp. 211-218. doi:10.1016/S0141-3910(02)00016-2

[28] X. Y. Wang, Y. M. Du, J. H. Yang, X. H. Wang, X. W. Shi and Y. Hu, "Preparation, Characterization and Antimicrobial Activity of Chitosan/Layered Silicate Nanocomposites," Polymer, Vol. 47, No. 19, 2006, pp. 6738-
6744. doi:10.1016/j.polymer.2006.07.026

[29] Z. Li, Y. M. Du, L. N. Zhang and D. W. Pang, "Preparation and Characterization of CDS Quantum Dots Chitosan Biocomposite," Reactive and Functional Polymers, Vol. 55, No. 1, 2003, pp. 35-43. doi:10.1016/S1381-5148(02)00197-9

[30] M. R. Guilherme, A. R. Fajardo, T. A. Moia., et al., "Porous Nanocomposite Hydrogel of Vinyled Montmorillonite-Crosslinked Maltodextrin-Co-Dimethylacryl-amide as a Highly Stable Polymer Carrier for Controlled Release Systems," European Polymer Journal, Vol. 46, No. 8, 2010, pp. 1465-1474. doi:10.1016/j.eurpolymj.2010.04.008

[31] T. Pojanavaraphan and R. Magaraphan, "Prevulcanized Natural Rubber Latex/Clay Aerogel Nanocomposites," European Polymer Journal, Vol. 44, No. 7, 2008, pp. 1968-1977. doi:10.1016/j.eurpolymj.2008.04.039

[32] Y. Li, L. Liu, W. A. Zhang and Y. E. Fang, "A New Hybrid Nanocomposite Prepared by Graft Copolymerization of Butyl Acrylate Onto Chitosan in the Presence of Organophilic Montmorillonite," Radiation Physics and Chemistry, Vol. 69, No. 6, 2004, pp. 467-471. doi:10.1016/j.radphyschem.2003.10.012

[33] A. Akelah, "Polymer-Clay Nanocomposites: Free-Radical Grafting of Polystyrene on to Organophilic Montmorillonite Interlayers," Journal of Material Sciences, Vol. 31, No. 13, 1996, pp. 3589-3596.

[34] Y. A. Zheng and A. Q. Wang, "Evaluation of Ammonium Removal Using a Chitosan-G-Poly (Acrylic Acid)/Rectorite Hydrogel Composite," Journal of Hazardous Materials, Vol. 171, No. 1-3, 2009. pp. 671-677. doi:10.1016/j.jhazmat.2009.06.053

[35] H. Y. Zhu, R. Jiang and L. Xiao, "Adsorption of an Anionic Azo Dye by Chitosan/Kaolin/ $\Gamma-\mathrm{Fe}_{2} \mathrm{O}_{3}$ Composites," Applied Clay Science, Vol. 48, No. 3, 2010, pp. 522-526. doi:10.1016/i.clay.2010.02.003

[36] C. A. P. Almeida, N. A. Debacher, A. J. Downs, L. Cottet and C. A. D. Mello, "Removal of Methylene Blue from Colored Effluents by Adsorption on Montmorillonite Clay," Journal of Colloid Interface Science, Vol. 332, No. 1, 2009, pp. 46-53. doi:10.1016/j.jcis.2008.12.012

[37] B. K. Nandi, A. Goswami and M. K. Purkait, "Removal of Cationic Dyes from Aqueous Solutions by Kaolin: Kinetic and Equilibrium Studies," Applied Clay Science, Vol. 42, No. 3-4, pp. 583-590. doi:10.1016/j.clay.2008.03.015 